\title{
The Pathogenesis of Nontraumatic Osteonecrosis
}

\author{
Jesse Seamon, Thomas Keller, Jamal Saleh, and Quanjun Cui \\ Department of Orthopaedic Surgery, University of Virginia School of Medicine, 400 Ray C. Hunt Drive, Box 800159, \\ Charlottesville, VA 22908, USA \\ Correspondence should be addressed to Quanjun Cui, qc4q@virginia.edu
}

Received 24 June 2012; Accepted 28 October 2012

Academic Editor: Pierre Youinou

Copyright () 2012 Jesse Seamon et al. This is an open access article distributed under the Creative Commons Attribution License, which permits unrestricted use, distribution, and reproduction in any medium, provided the original work is properly cited.

\begin{abstract}
Nontraumatic osteonecrosis continues to be a challenging problem causing debilitating major joint diseases. The etiology is multifactorial, but steroid- and alcohol-induced osteonecrosis contribute to more than two thirds of all cases with genetic risk factors playing an important role in many other cases, especially when they contribute to hypercoagulable states. While the exact mechanisms remain elusive, many new insights have emerged from research in the last decade that have given us a clearer picture of the pathogenesis of nontraumatic osteonecrosis of the femoral head. Progression to end stage osteonecrosis of the femoral head appears to be related to four main factors: interactions involving the differentiation pathway of osteoprogenitor cells that promote adipogenesis, decreased angiogenesis, direct suppression of osteogenic gene expression and proliferation of bone marrow stem cells, and genetic anomalies or other diseases that promote hypercoagulable states.
\end{abstract}

\section{Introduction}

Nontraumatic osteonecrosis (ON) of the femoral head continues to represent a significant challenge to orthopaedic surgeons [1-3] and is a devastating disease for affected patients with complete collapse of the femoral head occurring in $80 \%$ of untreated patients $[4,5]$. Nontraumatic conditions associated with ON are numerous $[1,2,6,7]$. Some of the well accepted and common associations include corticosteroid use $[8,9]$, alcohol abuse [10], systemic lupus erythematous [11], hemoglobinopathies including sickle cell anemia [1214], Legg-Calve Perthes disease [15], and exposure to radiation [16] or cytotoxic agents [17]. Other less common associations include Gaucher's disease [11, 18, 19], dysbarisms [4], HIV [20], hyperlipidemia [21], pancreatitis, and gout [22]. A substantial number of cases have no identifiable etiologic factors and have been referred as idiopathic [23]. The pathogenic mechanisms leading to impaired circulation in these conditions are most likely multifactorial [3, 21, 24, 25]. Mechanical blood vessel interruption, thrombotic intravascular occlusion, and extravascular compression are the three most commonly accepted general mechanisms leading to ON $[1,3,24,26]$. Recent attention has been given to the interplay between individual genetic predisposition and environmental factors related to ON [26-50]. Both heritable and acquired risk factors for femoral head ON related to hypercoagulability [28, 32-36, 47, 50-52], hemoglobinopathies [27, 28,36 ], steroids [48], angiogenesis [43], and oxidative stress [45] have been identified in many patients. Technological advances in molecular biology have enabled studies on the advanced mechanisms of steroid and alcohol-induced ON [9, 10, 53-73]. Preliminary data with statins and low molecular weight heparin from clinical studies are promising (Table 1) $[74,75]$. Still, the exact pathogenesis of $\mathrm{ON}$ is controversial and poorly understood. This limited knowledge has impeded the development of any effective prophylaxis or pharmacologic treatment for this debilitating disease $[1,6]$. Currently, the primary effective treatments are surgical, consisting of unloading osteotomies, vascularized grafts, and total hip replacements $[4,5,21,26]$. This report seeks to systematically review the more common causes of pathogenesis of nontraumatic ON of the femoral head, which include steroids, alcohol, genetic factors, and hypercoagulability.

\section{Pathophysiology of Osteonecrosis}

Ultimately, $\mathrm{ON}$ of the femoral head occurs through one final common pathway, which is decreased blood flow to the femoral head that leads to bone ischemia and death $[1,3$, 21, 24] (Figure 1). However, the precipitating mechanisms 
TABLE 1: New developments on pathogenesis of nontraumatic osteonecrosis and its clinical significance.

\begin{tabular}{ll}
\hline New findings & Clinical significance \\
\hline $\begin{array}{l}\text { Steroids enhance adipogenesis and inhibit osteogenesis and angiogenesis by } \\
\text { marrow stem cells }[53,54,56]\end{array}$ & $\begin{array}{l}\text { Therapeutic modulating marrow stem cell } \\
\text { Statins have shown therapeutic effects } \\
{[54,56,74]}\end{array}$ \\
$\begin{array}{l}\text { Alcohol stimulate adipogenesis and inhibit osteogenesis by marrow stem cells } \\
{[40,65]}\end{array}$ & Therapeutic modulating marrow stem cell \\
$\begin{array}{l}\text { Heritable hypofibrinolysis and thrombophilia }[32,34,40,50,72] \\
\text { Genetic associations }\end{array}$ & Anticoagulation therapy is effective [75] \\
Mutations in the COL2A1 gene [30] & Familial high risk group \\
Polymorphisms in alcohol metabolizing enzyme gene [29] & High risk subgroup \\
Polymorphisms in the multidrug resistance gene $1[73]$ & Screening high risk patients [73] \\
\hline
\end{tabular}

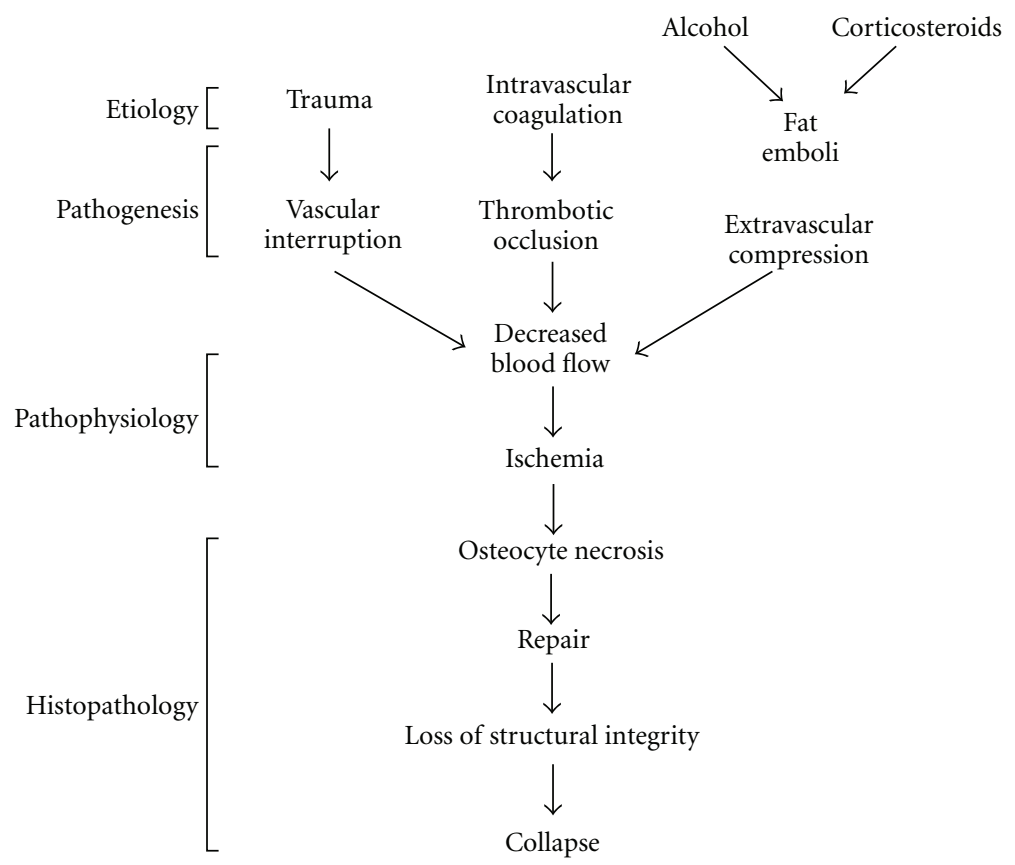

FIGURE 1: Schematic representation of the development of osteonecrosis. (Reprinted, with permission, from [24].)

which lead to this final pathway are varied. Vascular occlusion can be caused by local thrombi, fat emboli, nitrogen bubbles, or abnormally shaped red blood cells [52, 76-78]. Extravasated blood along with fat or cellular elements in the marrow cavity can extrinsically compress both arteries and veins $[7,10,54,79,80]$. The blood vessels in the femoral head may be directly damaged by vasculitis, irradiation, or chemical toxicity $[1,2,7]$. Bone cells may remain viable if the collateral circulation is sufficient. Although bone has a relatively rich vascular supply, the distribution is inhomogeneous and leaves some areas more vulnerable than others $[7,81]$. Once the ischemic threshold is reached, the morphologic changes within the affected bone are similar regardless of the inciting disorder.

No histologic evidence of damage is evident until twenty-four to seventy-two hours after vascular compromise [81]. Examination of the bone marrow reveals necrosis of hematopoietic cells, endothelial cells, and lipocytes. Osteocytes atrophy and die, and increasing numbers of empty lacunae become evident with time. The release of lysosomes acidifies the surrounding tissue as dying lypocytes release free fatty acids which saponify with extracellular calcium to form insoluble soaps. A subsequent increase in fatty marrow water content is detectable by magnetic resonance imaging (MRI) and represents the earliest abnormality seen clinically.Saponified fats and other necrotic areas eventually calcify and can be detected by plain radiographs later in the disease process [81-83].

Cell death is followed by initiation of the repair process. An inflammatory cascade is initiated by the adjacent viable tissues, which leads to a fibrous vascular in growth in the regions of cell death. Vascular canals can be seen penetrating the medullary canals of the cancellous bone and the haversian canals in the overlying cortical bone. These vessels are accompanied by primitive mesenchymal cells which differentiate into osteoblasts and osteoclasts [81-84]. Immature woven bone is deposited throughout the network of dead trabecular bone. The nonviable trabecular bone 
is slowly resorbed by the process of creeping substitution. Unfortunately, the newly deposited bone does not attain the previous structural integrity of that region of the femoral head, leading to subchondral collapse of these regions at appropriate weight bearing loads. Ultimately, this leads to irregularities in the normally smooth cartilaginous surface of the femoral head that progress to end-stage arthritis. Additionally, surrounding viable bone may lose mass and become osteopenic from relative patient inactivity over the course of the disease $[1,25,81-84]$.

\section{Historical Views on the Pathogenesis of Osteonecrosis}

Phemister was the first to propose that the "aseptic necrosis" might result from fractures, bone graft transplantation, radiation and vascular obstruction from thrombosis, or embolization [85]. ON was later regarded as a primitive vascular problem. Some believed that ON of the femoral head resulted from a type of vasculitis [86]. Chandler implicated an extraosseous embolic process and introduced the concept of "coronary disease of the hip" [87]. In a microangiographical study of 31 femoral heads with idiopathic ON, Atsumi found extraossesous interruption of the superior retinacular arteries along with early angiogenesis and compensatory hypertrophy of the unaffected surrounding vasculature. They also found blockage of revascularization occurring along the areas of subchondral collapse in the weight-bearing region [88]. In contrast, Glimcher and Kenzora found no evidence to support blood vessel involvement in 150 adult femoral heads with ON and instead implicated a purely metabolic syndrome leading to cell death [82-84].

Many theories regarding the pathogenesis of nontraumatic ON have been proposed over the past twenty years $[1,6,21,24]$. Intraosseous hypertension, intravascular fat or gaseous emboli, and extravascular compression by increased marrow fat stores are several accepted theories [7, 52, 54, 78-80, 89-91]. Most support a "multiple hit" theory, with accumulated tissue stress from various insults reaching a critical threshold and initiating the disease process $[1,25]$. Many would agree that these theories are not mutually exclusive, but are instead mutually supportive.

\section{Association of Osteonecrosis with Hypercoagulopathy and Genetic Alterations}

Paul-Jones first suggested that hypercoagulability, and in specific intravascular coagulation could be a cause of ON in 1992 [77]. Thrombotic occlusion of the microcirculation can occur from hereditary thrombophilia, impaired fibrinolysis or antiphospholipid antibodies [16]. Additional causes include environmental or acquired/preexisting conditions, such as hyperlipidemia, hypersensitivity reactions, thromboplastin release during pregnancy, malignant tumors, and inflammatory bowel disease all may contribute additional risk to individuals with an underlying genetic predisposition to form microvascular thrombi $[16,21,26,29,32,34,50,72$, $73,75,78,92-94]$. The role of sickle cell disease and other hemoglobinopathies in promoting $\mathrm{ON}$ of the femoral head has been well documented and also seems to act through the final pathway of intravascular coagulation [12-14, 95-98].

Björkman et al. showed in a retrospective study of 63 adult patients with osteonecrosis of the femoral head, that mutations in the factor $\mathrm{V}$ Leiden or the prothrombin 20210A gene were significantly more frequent in patients with idiopathic osteonecrosis than in patients with steroid or alcohol-induced osteonecrosis, as well as in a population of healthy control subjects [99]. This is supported by Zalavras and his colleagues who have demonstrated that the factor $\mathrm{V}$ Leiden mutation was presented in $18 \%$ of 72 adult Caucasian patients, compared with $4.6 \%$ of 300 healthy control subjects [50]. In addition, protein $C$ and protein $S$ deficiencies, which lead to thrombophilia have been associated with ON of the femoral head [32]. Jones et al. have studied the blood samples of 45 patients with osteonecrosis, 5 of which had no known preexisting conditions that could cause $\mathrm{ON}$ otherwise. In comparison to 40 age matched healthy controls, patients with $\mathrm{ON}$ were 3 times more likely to have a gene abnormality promoting anticoagulation, and further in those with no preexisting condition $100 \%$ had a gene abnormality promoting anticoagulation [40]. Glueck et al. have done extensive work in profiling the role of hypercoagulability and $\mathrm{ON}[30,33-35,72,75,93]$. In a population of 36 patients entering a treatment trial with low-molecularweight heparin (LMWH) for treatment of femoral head osteonecrosis they found gene polymorphisms that resulted in increased activity of the plasminogen activator inhibitor-1 gene (PAI-1), alterations in the methylenetetrahydrofolate reductase (MTHFR), and resultant hypofibrinolysis concurrent with higher homecysteine and lipoprotein levels than controls [34]. In this same group of patients, they showed that enoxaparin prevented progression of osteonecrosis in patients with early stage disease [75]. Chang et al. found that polymorphism in the MTHFR gene increased the risk for ON in the Korean population [28], while Kim et al. were unable to show a significant association between single nucleotide polymorphisms (SNPs) in the MTHFR gene locus and development of ON in the Korean population [42].

It has become clear that in general, genetic anomalies or heritable diseases that promote intravascular coagulation are associated with the development of osteonecrosis. Future studies will likely focus on ways to screen for and localize polymorphisms associated with hypercoagulability, so that earlier or perhaps even prophylactic treatment can be provided for this patient population.

4.1. Genetic Associations. As previously discussed, thrombophilic disorders caused by both heritable diseases and genetic anomalies such as SNPs play a major role in the etiology and progression of $\mathrm{ON}$ due to genetic alterations in key components in the coagulation cascade including Protein C, Protein S, PAI-1, and a number of other factors [12$14,16,27,30,33-35,72,78,93,95-98]$. Chen et al. evaluated two Taiwanese pedigrees with familial autosomal dominant osteonecrosis of the femoral head. They were able to link the presence of mutations in the Protein C, Protein S, and 
PAI-1 proteins to the $2 \mathrm{q} 13-\mathrm{q} 14,3 \mathrm{q} 11.1-\mathrm{q} 11.2$ and $7 \mathrm{q} 21.3-$ q22 chromosomal segments respectively [30]. Pierre-Jacques et al. have reported on a familial heterozygous Protein $S$ deficiency in a patient with multifocal osteonecrosis [49].

Numerous other genetic associations have been identified [27, 28, 31, 33, 35-38, 43-48]. Glueck et al. demonstrated that the T-786C Drosophila nitric-oxide synthase (dNOS) SNP results in decreased activity of nitric oxide which is responsible for promoting angiogenesis, bone formation, and inhibiting platelet aggregation. 22\% of patients with idiopathic ON in their series had this SNP compared to only $5 \%$ of controls $[33,35]$. Similarly, Koo et al. have found that polymorphisms in the nitric oxide synthase gene increased the risk of ON in their study population [47]. Hong et al. evaluated SNP in the transferrin (TF), vascular endothelial growth factor C (VEGFC), sterol regulatory element binding transcription protein-3 (IGFBP3), and angiotensin I converting enzyme (ACE) genes in a comparison study between 450 patients with femoral head ON and 300 matched healthy controls. They found that the SNP R2453839S, SNP on the IGFBP3 gene was significantly associated with development of ON and SNPs in the ACE gene were associated with increased chance of progression of steroid induced $\mathrm{ON}$. Surprisingly, they found that SNPs in thekinase insert domain receptor (KDR) and neuropilin 1 (NRP1) gene loci were associated with decreased prevalence of ON [38]. Kim et al. have done extensive work in the Korean population to identify possible genes where SNPs may be related to increased development on ON [38, 41,43-46]. They have identified SNPs in the SREBP-2 gene [41], interleukin receptor 23 gene [44], annexin gene family [46], catalase gene [45], and promoter polymorphisms in the VEGF gene [43]. Dai et al. have shown that polymorphisms in genes that inhibit the tissue factor pathway may lead to increased risk of osteonecrosis [31]. Beyond the previously discussed genes, polymorphisms invitamin D receptor (VDR) gene, the thymidylate synthase gene (TYMS), and the Type II collagen A1 (COL2A1) gene have all been identified as increasing the risk of ON of the femoral head [36].

Not all patients receiving high-dose steroids develop ON. Asano et al. have postulated that differences in drug metabolism related to genetic variation may explain why some develop ON while others do not $[73,92]$. They examined 136 patients after a kidney transplant and found a strong association between those expressing a specific nucleotide polymorphism in the gene encoding the transport protein P-glycoprotein (P-gp) and resistance to ON. P-gp plays an important role in the absorption and distribution of drugs. By measuring serum through levels of tacrolimus, an immunosuppressive drug whose bioavailability is known to be influenced by P-gp, they were able to correlate enhanced $\mathrm{P}$-gp activity with resistance to ON. The increased P-gp activity may lead to more rapid steroid clearance and subsequently lower serum steroid concentrations. Furthermore, they found that individuals expressing the C3435TT genotype of the gene encoding P-gp had significantly higher P-gp activity and a significantly lower incidence of ON. Their results demonstrate a genetically linked resistance to steroidinduced ON in patients with the C3435TT genotype of the gene encoding P-gp [73, 92]. He and Li have shown that the $\mathrm{P}$-glycoprotein gene ABCB1 which modulates glucocorticoid uptake may be associated with development of ON [37]. In a comparison of patients on chronic glucocorticoids with and without ON they found that the G2677T/A SNP was associated with development of steroid induced ON [37]. Kim et al. also found SNPs in the ABCB1 (c3435t) gene to be related to increased sensitivity to steroid induced $\mathrm{ON}$ and found that concomitant SNPs in the CBP (r3751845s) gene increased the relative sensitivity [45].

Chao et al. proposed that genetic polymorphisms may influence the occurrence of alcohol-induced osteonecrosis [29]. Polymorphisms of several alcohol-metabolizing enzymes were evaluated in alcoholic patients with hip osteonecrosis, pancreatitis, and cirrhosis of the liver. They found that allele frequencies of $\mathrm{ADH}_{2}{ }^{*} 1$ (alcohol dehydrogenase) and ALDH2*2(aldehyde dehydrogenase) differed among these disease-defined subpopulations of alcoholics, suggesting that differences in the alcohol metabolizing enzyme genes may be responsible for different organ-specific complications [29].

As our knowledge about to the genetic basis of ON improves, so too will our ability to identify at-risk individuals. Certainly, genetic polymorphisms in the genes that help us to metabolize alcohol and steroids along with alterations in the genetic make-up of genes involved in the coagulation cascade seem to be the main candidates for increasing risk to non-traumatic femoral head osteonecrosis.

\section{Steroid and Alcohol-Induced Osteonecrosis}

Exogenous corticosteroids and alcohol have all been associated with nontraumatic osteonecrosis. The dose affects of these substances and exact mechanism by which they produce osteonecrosis remains unknown though currently a topic of investigation.

5.1. Steroids. The association between excessive corticosteroid use and the development of $\mathrm{ON}$ has been well established since the first case report in a patient with rheumatoid arthritis in 1957 [100]. The incidence of ON has increased in parallel with the rise in glucocorticoid therapy for treatment of systemic conditions as well as organ transplantation. Of the 30 million Americans currently receiving glucocorticoid therapy, as many as $40 \%$ will develop some degree of osteonecrosis [70, 101]. Glucocorticoids are the most common cause of nontraumatic osteonecrosis [23]. Patients receiving steroid therapy have an approximately 20-fold increase in their likelihood of developing ON [8]. Though the dose effect of corticosteroid therapy on osteonecrosis remains largely unknown, recent studies suggest that corticosteroid doses above $25-40 \mathrm{mg} /$ day are significant risk factors for nontraumatic ON in renal transplant and SLE patients [94, 102]. Several hypotheses regarding the cause of steroid-induced ON are based around the notions of small vessel occlusion by fatty emboli and the impedance of sinusoidal blood flow secondary to a rise in intraosseous pressure due to fatty infiltration following steroid therapy. While contributing factors from underlying disease processes 


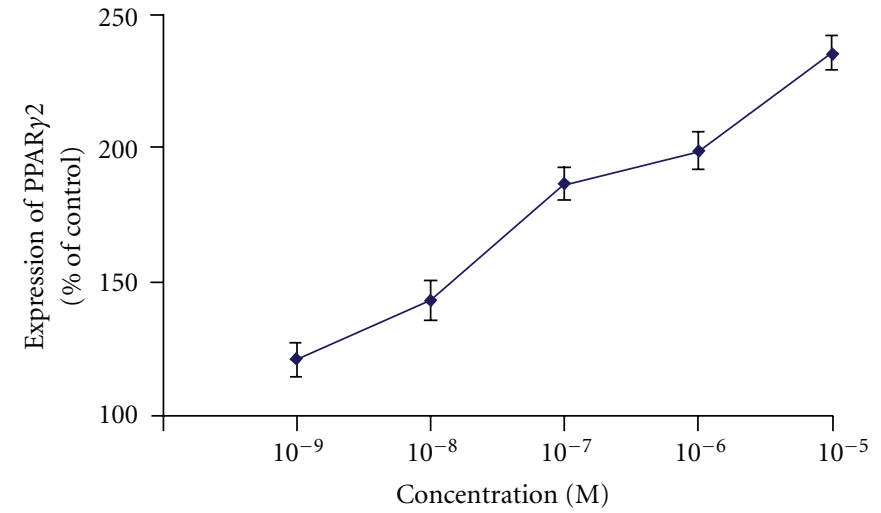

(a)

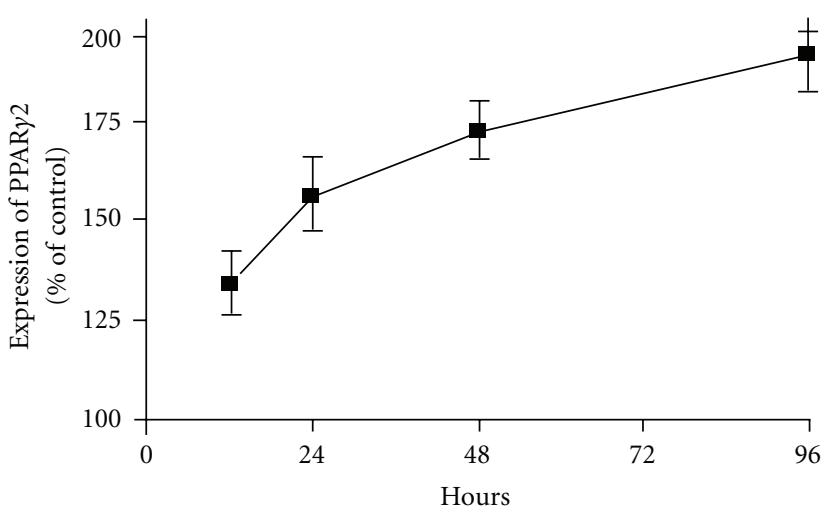

(b)

FIGURE 2: PPAR $\gamma 2$ upregulation by dexamethasone is concentration and time dependent. Quantitation of the relative PPAR $\gamma 2$ gene expression of the D1 cells treated with (a) different concentrations of dexamethasone for $48 \mathrm{~h}$ and (b) $10^{-7}$ mol/L dexamethasone for different time points. Error bars represent the standard deviation of triplicate experiments $\left({ }^{*} P<0.05\right)$. (Reprinted, with permission, from: [56].)

confound this condition, elucidating the mechanism responsible for $\mathrm{ON}$ in patients using corticosteroids has been an area of intense research.

Studies have revealed abnormalities of lipid metabolism in both humans and animals following exposure to corticosteroids [80, 103-106]. In animal studies, induced hypercortisolism resulted in adipocyte hypertrophy, hyperlipidemia, fatty liver, and systemic fat emboli. Although marrow edema and fatty necrosis was frequently observed, in quadrupedal studies, no area of bone necrosis or articular collapse could be identified. On the other hand, chickens treated with steroids did show evidence of $\mathrm{ON}$, suggesting that differences in biomechanics between bipedal and quadrupedal species may be an important contributing factor [54].

Studies in mice and humans have shown that dexamethasone, given in a dose and time-dependent fashion, induces the differentiation of bone marrow derived stem cells into adipocytes, while inhibiting osteogenesis $[53,65,71,79]$. Fat cell hypertrophy has been observed in histologic specimens of human femoral heads following treatment with dexamethasone for 5 days [62]. Dexamethasone has been shown to inhibit the expression of type-I collagen and osteocalcin, thereby suppressing the differentiation of bone marrowderived stem cells into osteoblasts [53]. Prednisolone therapy has been found to decrease bone density and cancellous bone area while causing trabecular narrowing [107]. Mesenchymal stem cells derived from patients with corticosteroid-induced osteonecrosis of the femoral head have been shown to have lower proliferative ability, which may explain the low capacity for bone regeneration in these patients [68].

Lovastatin, when added to cell culture medium, had been found to inhibit adipogenesis and fat-specific gene expression caused by dexamethasone supplementation [54]. Additionally, lipid lowering agents counteract the inhibitory effect of steroids on osteoblastic gene expression [54]. These findings have been demonstrated both in vitro and in vivo $[54,74,79]$. In a supporting study, mesenchymal cells transplanted into host mice following transfection with a traceable gene demonstrated increased adipogenesis following systemic steroid treatment [108]. Based on these observations, it has been postulated that steroid-induced $\mathrm{ON}$ may be due to intraosseous hypertension from excessive marrow fat accumulation or a shift in the differentiation of marrow stem cells into adipocytes, resulting in a reduction in the pool of stem cells available for osteoblast production, ultimately leading to insufficient repair and remodeling of necrotic bone.

The mechanisms by which steroid-treated mesenchymal stem cells demonstrate increased adipogenesis and decreased osteogenesis have been studied at the molecular level [53, 55, 56]. Peroxisome proliferator activated receptor- $\gamma$ (PPAR- $\gamma$ ) and core-binding factor a1 (Cbfa1) are transcription factors found to be important in the differentiation of pluripotent cells into adipogenic and osteogenic cell lines, respectively. Dexamethasone has been shown to increase mRNA expression of PPAR- $\gamma$ (Figure 2) and decrease mRNA expression of Cbfa1 (Figure 3). These findings support the idea that dexamethasone promotes adipogenesis while inhibiting osteogenesis. Additionally, these studies also suggest that dexamethasone impairs angiogenesis by suppressing the production of VEGF (Figure 4). Osteoblasts derived from femoral heads have been found to exhibit downregulation of VEGF within 24 hours of incubation with glucocorticoids [67]. In a rabbit steroid-induced osteonecrosis model, however, VEGF levels increased to peak levels 3 days after methylprednisolone treatment [59]. These studies suggest that while steroids inhibit VEGF expression in isolated osteoblast cultures, steroid associated ischemic events occurring in vivo likely contribute to an upregulated VEGF response. The shunting of osteoprogenitor cells into the adipocytic pathway in conjunction with the suppression of angiogenic growth factor production may at least partially explain the basis of steroid-induced ON.

Using a porcine model, Drescher et al. investigated the effects of methylprednisolone on the response of femoral head epiphyseal arteries to vasoactive substances [57]. 


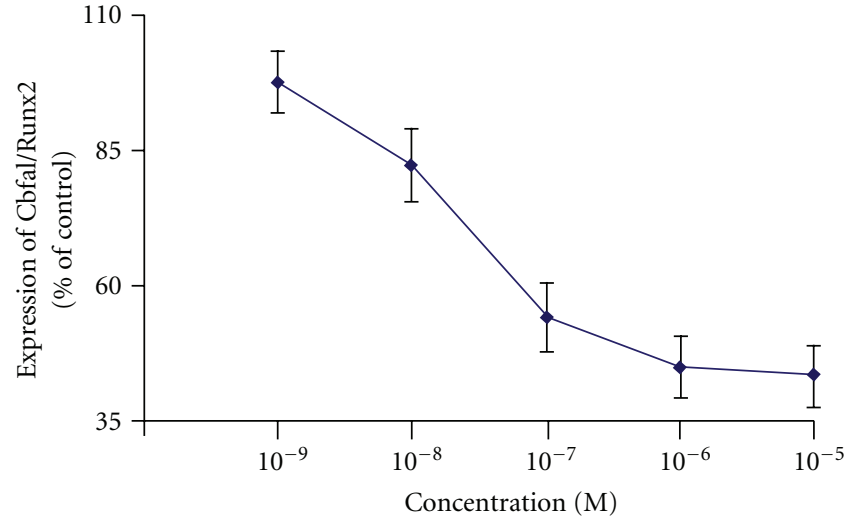

(a)

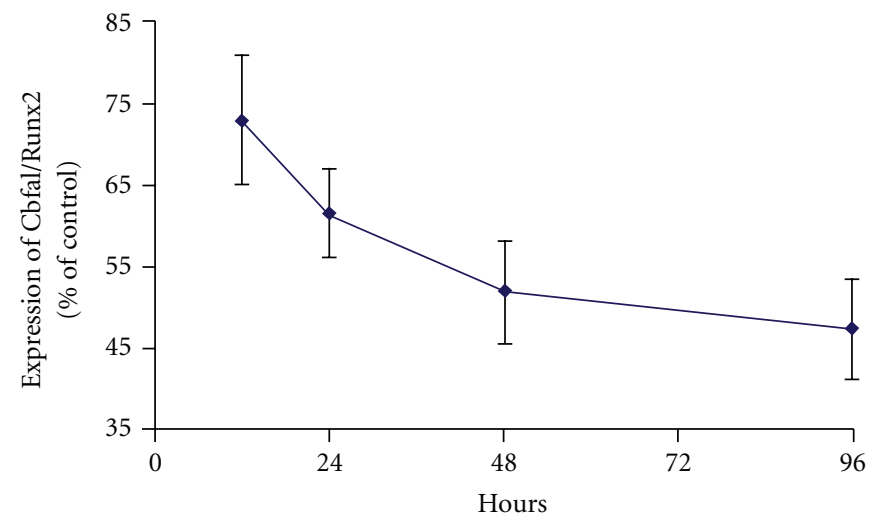

(b)

FIGURE 3: Concentration and time response of Cbfa1/Runx2 mRNA downregulation by dexamethasone. Quantitation of the relative Cbfa1/Runx2 gene expression of the D1 cells treated with (a) different concentrations of dexamethasone for $48 \mathrm{~h}$ and $(\mathrm{b}) 10^{-7} \mathrm{~mol} / \mathrm{L}$ dexamethasone for different time points. Error bars represent the standard deviation of triplicate experiments $\left({ }^{*} P<0.05\right)$. (Reprinted, with permission, from: [56].)

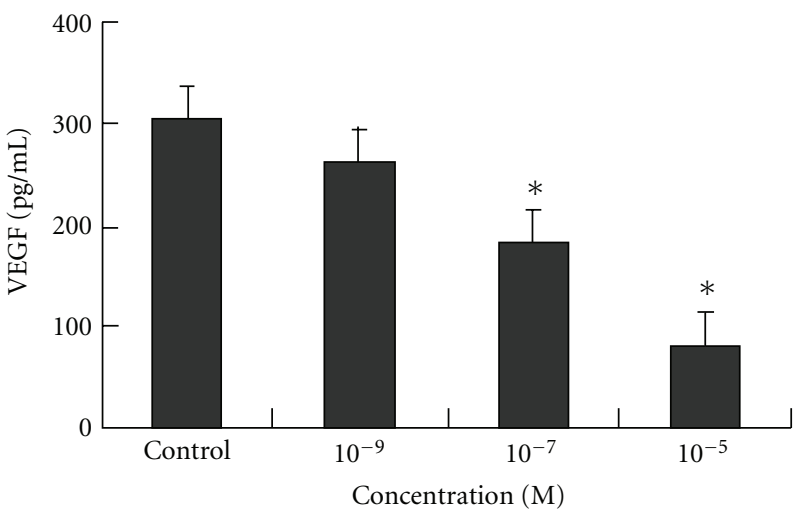

(a)

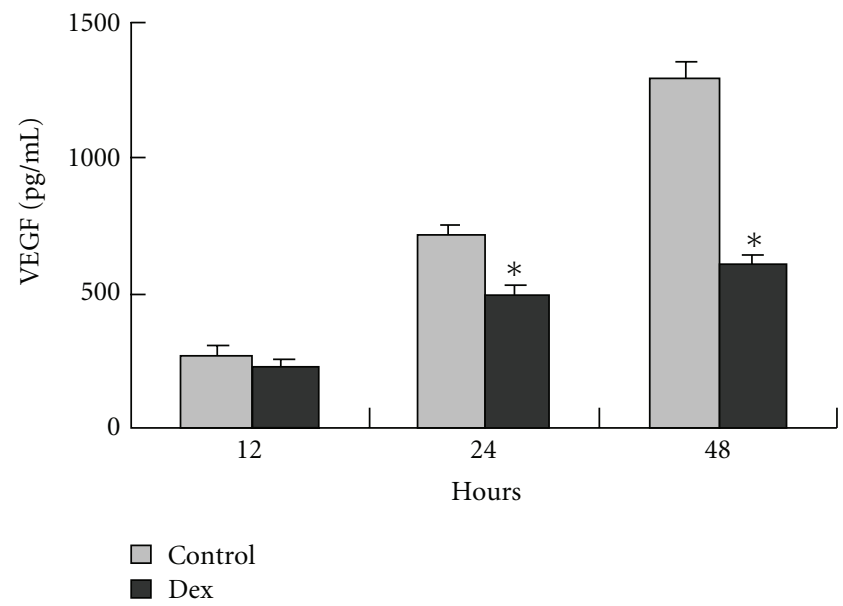

(b)

FIGURE 4: Inhibition of VEGF production of D1 cells by dexamethasone is dose and time dependent. VEGF expression in supernatant medium of the D1 cells treated with (a) different concentrations of dexamethasone for $24 \mathrm{~h}$ and (b) $10^{-7}$ mol/L dexamethasone for different time points was assessed by ELISA. Each column shows mean $\pm \mathrm{SD}$ of data from three experiments $\left({ }^{*} P<0.05\right)$. (Reprinted, with permission, from: [56].)

Steroid-treated vessels demonstrated an increased response to endothelin-1 and a decreased response to bradykinin in comparison to untreated controls. Because endothelin-1 effectively vasoconstricts while bradykinin vasodilates, the overall conclusion of this work is that methylprednisolone, when coupled with vasoactive substances, modulates femoral head epiphyseal artery contraction. These findings support the hypothesis that the pathomechanism of steroid-induced femoral head $\mathrm{ON}$ is related to disturbed femoral head blood flow.

Ischemia and subsequent reperfusion of the femoral head is also thought to contribute to ON. Drescher et al. studied the influence of short-term high-dose steroid treatment on femoral head reperfusion following ischemic insult in a porcine model [109]. Femoral head ischemia was achieved by pressurizing the hip to $250 \mathrm{~mm} \mathrm{Hg}$ for 6 hours. Radiolabeled microspheres released into the bloodstream were used to estimate blood flow to the femoral head. In comparison to untreated controls, methylprednisolone treatment was not shown to have an effect on reperfusion of the femoral head following an ischemic insult. Despite these findings, baseline blood flow was profoundly reduced in groups treated with methylprednisolone.

Zaidi et al. have suggested that adrenocorticotropic hormone (ACTH) may protect against methylprednisoloneinduced osteonecrosis of the femoral head [9]. In preliminary studies, this group documented functional ACTH receptors on osteoblasts which, when activated, enhanced osteoblastic proliferation [110]. In an in vivo osteonecrosis model, rabbits treated with depomedrol plus ACTH for 
1 month demonstrated fewer signs of trabecular necrosis and increased expression of VEGF in comparison to groups treated with the steroid depomedrol alone [9]. Though statistical significance was not reached, quantitative DXA and tetracycline labeling showed a trend towards greater femoral head density and subarticular bone integrity in groups treated with ACTH. These findings support further examination into the efficacy of ACTH in preventing steroidinduced osteonecrosis.

5.2. Alcohol. One study showed a clear increase in the risk of femoral head $\mathrm{ON}$ in individuals consuming greater than $400 \mathrm{~mL}$ of alcohol per week [111]. Mouse and rabbit in vitro studies investigating the effect of alcohol on bone marrow stromal cells demonstrate that alcohol induces the differentiation of marrow stromal cells into adipocytes in a dose dependent manner [10]. Alcohol-induced a significant increase in serum triglyceride and cholesterol levels, in addition to liver and bone marrow fatty infiltration. In the subchondral areas of the femoral head, fat cell hypertrophy and proliferation were observed. Triglyceride deposition in osteocytes lead to pyknosis and an increased percentage of empty osteocyte lacunae. None of these findings were apparent in untreated control groups. Alcohol treated groups demonstrated intracellular lipid deposition which ultimately lead to death of osteocytes. Cells treated with ethanol showed diminished alkaline phosphatase activity and expression of osteocalcin. Similar to the effects of corticosteroids, alcohol increases adipogenesis and decreases osteogenesis. Unlike the effect of steroids on stromal cells, alcohol-treated cells did not show increases in PPAR- $\gamma$ expression, supporting the idea that alcohol influences fatty acid metabolism through a differing mechanism.

Wang et al. have suggested, from in vitro and in vivo studies, that the Chinese herbal puerarin, with its antioxidative and antithrombotic effects, can prevent alcohol-induced osteonecrosis [69]. Cells treated with ethanol for 21 days, and mice treated with ethanol for up to 10 months demonstrated a decrease in alcohol-induced adipogenic gene expression when treated simultaneously with puerarin. It is postulated that the inhibitive effects of puerarin on bone-marrow adipogenesis leads to diminished fat marrow changes and subsequent maintenance of osteogenic differentiation of marrow stem cells.

In a study by Suh et al., marrow was collected from the proximal femurs of 33 patients following hip replacement for either alcohol-induced osteonecrosis of the femoral head or femoral neck fractures [65]. After isolating the mesenchymal stem cells and expanding them in culture, cells obtained from the osteonecrotic hips showed diminished osteogenic differentiation as compared to cells taken from fractured hips.

The critical dose of corticosteroids and alcohol necessary to induce $\mathrm{ON}$ is largely unknown. It appears that serum corticosteroid concentration is a more important risk factor than cumulative dose or duration of therapy. There exists a strong association between daily total dose and oral dosing (as opposed to parenteral dosing) of corticosteroids in patients with femoral head ON [112]. Most cases of femoral head ON occur after high-dose oral corticosteroid treatment for longer than 1 month, though rare cases have occurred after shorter treatment intervals [113]. Changes indicative of evolving femoral head $\mathrm{ON}$ have been appreciated on MRI within three months in patients treated with high-dose prednisolone for $4-8$ weeks [114]. These changes occurred prior to symptomatic onset.

From these studies it seems clear that both steroids and alcohol promote adipogenesis at the expense of osteoblastic proliferation or function. Although the exact molecular mechanisms may differ between these two implicating substances, the consequences of increased marrow fat, impaired vascularity, and diminished reparative capability all contribute to the final pathway of cell death. The role of an underlying genetic predisposition in the development of $\mathrm{ON}$ in these patients has not been fully elucidated but could explain why some chronic users of steroids or alcohol fail to acquire the disease $[29,73,92]$.

In summary, the exact pathogenesis of $\mathrm{ON}$ is still unknown. However, many new insights have emerged from research in the last decade (Table 1). Recent studies have demonstrated that both steroids and alcohol promote adipogenesis while inhibiting osteogenesis and angiogenesis, leading to osteonecrosis and osteoporosis. Genetic factors and heritable coagulopathy including hypofibrinolysis and thrombophilia may also play an important role in the development of ON. Statins and anticoagulation therapy have shown promise in amelioration of ON. Further investigation in this area is needed.

\section{Acknowledgments}

The study is supported by Orthopaedic Research and Education Foundation/Zachary B. Friedenberg, MD, Clinician Scientist Award and a Grant from Arthritis National Research Foundation.

\section{References}

[1] J. Arlet, "Nontraumatic avascular necrosis of the femoral head: past, present, and future," Clinical Orthopaedics and Related Research, no. 277, pp. 12-21, 1992.

[2] B. Jacobs, "Epidemiology of traumatic and nontraumatic osteonecrosis," Clinical Orthopaedics and Related Research, vol. 130, pp. 51-67, 1978.

[3] M. A. Mont and D. S. Hungerford, "Non-traumatic avascular necrosis of the femoral head," Journal of Bone and Joint Surgery, vol. 77, no. 3, pp. 459-474, 1995.

[4] M. A. Mont, L. C. Jones, and D. S. Hungerford, "Current concepts review-nontraumatic osteonecrosis of the femoral head: ten years later," Journal of Bone and Joint Surgery, vol. 88, no. 5, pp. 1117-1132, 2006.

[5] M. A. Mont, G. A. Marulanda, L. C. Jones et al., "Systematic analysis of classification systems for osteonecrosis of the femoral head," Journal of Bone and Joint Surgery, vol. 88, no. 3, pp. 16-26, 2006.

[6] G. Etienne, M. A. Mont, and P. S. Ragland, "The diagnosis and treatment of nontraumatic osteonecrosis of the femoral head," Instructional Course Lectures, vol. 53, pp. 67-85, 2004.

[7] D. S. Hungerford and D. W. Lennox, "The importance of increased intraosseous pressure in the development of 
osteonecrosis of the femoral head: implications for treatment," Orthopedic Clinics of North America, vol. 16, no. 4, pp. 635-654, 1985.

[8] M. Sakaguchi, T. Tanaka, W. Fukushima, T. Kubo, and Y. Hirota, "Impact of oral corticosteroid use for idiopathic osteonecrosis of the femoral head: a nationwide multicenter case-control study in Japan," Journal of Orthopaedic Science, vol. 15, no. 2, pp. 185-191, 2010.

[9] M. Zaidi, L. Sun, L. J. Robinson et al., "ACTH protects against glucocorticoid-induced osteonecrosis of bone," Proceedings of the National Academy of Sciences of the United States of America, vol. 107, no. 19, pp. 8782-8787, 2010.

[10] Y. Wang, Y. Li, K. Mao, J. Li, Q. Cui, and G. J. Wang, "Alcoholinduced adipogenesis in bone and marrow: a possible mechanism for osteonecrosis," Clinical Orthopaedics and Related Research, no. 410, pp. 213-224, 2003.

[11] M. Abu-Shakra, D. Buskila, and Y. Shoenfeld, "Osteonecrosis in patients with SLE," Clinical Reviews in Allergy and Immunology, vol. 25, no. 1, pp. 13-23, 2003.

[12] A. L. Akinyoola, I. A. Adediran, C. M. Asaleye, and A. R. Bolarinwa, "Risk factors for osteonecrosis of the femoral head in patients with sickle cell disease," International Orthopaedics, vol. 33, no. 4, pp. 923-926, 2009.

[13] J. Buck and S. C. Davies, "Surgery in sickle cell disease," Hematology/Oncology Clinics of North America, vol. 19, no. 5, pp. 897-902, 2005.

[14] M. M. Mukisi, K. Bashoun, and F. Burny, "Sickle-cell hip necrosis and intraosseous pressure," Orthopaedics and Traumatology: Surgery and Research, vol. 95, no. 2, pp. 134-138, 2009.

[15] E. J. Wall, "Legg-Calve-Perthes' disease," Current Opinion in Pediatrics, vol. 11, no. 1, pp. 76-79, 1999.

[16] J. C. Rueda, M. A. Q. Duque, R. D. Mantilla, and A. IglesiasGamarra, "Osteonecrosis and antiphospholipid syndrome," Journal of Clinical Rheumatology, vol. 15, no. 3, pp. 130-132, 2009.

[17] K. Shim, M. J. MacKenzie, and E. Winquist, "Chemotherapyassociated osteonecrosis in cancer patients with solid tumours: a systematic review," Drug Safety, vol. 31, no. 5, pp. 359371, 2008.

[18] V. Bubbar, F. Las Heras, D. Amato, K. P. H. Pritzker, and A. E. Gross, "Total hip replacement in Gaucher's disease: effects of enzyme replacement therapy," Journal of Bone and Joint Surgery, vol. 91, no. 12, pp. 1623-1627, 2009.

[19] E. Lebel, M. Phillips, D. Elstein, A. Zimran, and M. Itzchaki, "Poor results of drilling in early stages of juxta-articular osteonecrosis in 12 joints affected by Gaucher disease," Acta Orthopaedica, vol. 80, no. 2, pp. 201-204, 2009.

[20] M. A. Matos, R. W. de Alencar, and S. S. da Rocha Matos, "Avascular necrosis of the femoral head in HIV infected patients," Brazilian Journal of Infectious Diseases, vol. 11, no. 1, pp. 31-34, 2007.

[21] J. R. Lieberman, D. J. Berry, M. A. Mont et al., "Osteonecrosis of the hip: management in the 21st century," Instructional Course Lectures, vol. 52, pp. 337-355, 2003.

[22] D. P. Baksi, A. K. Pal, and D. D. Baksi, "Long-term results of decompression and muscle-pedicle bone grafting for osteonecrosis of the femoral head," International Orthopaedics, vol. 33, no. 1, pp. 41-47, 2009.

[23] Y. Assouline-Dayan, C. Chang, A. Greenspan, Y. Shoenfeld, and M. E. Gershwin, "Pathogenesis and natural history of osteonecrosis," Seminars in Arthritis and Rheumatism, vol. 32, no. 2, pp. 94-124, 2002.
[24] R. K. Aaron, "Osteonecrosis: etiology, pathophysiology and diagnosis," in The Adult Hip, J. J. Callaghan, A. G. Rosenberg, and H. Rubash, Eds., Lippencott-Raven, Philadelphia, Pa, USA, 1998.

[25] J. E. Kenzora and M. J. Glimcher, "Accumulative cell stress: the multifactorial etiology of idiopathic osteonecrosis," Orthopedic Clinics of North America, vol. 16, no. 4, pp. 669679, 1985.

[26] L. C. Jones and D. S. Hungerford, "Osteonecrosis: etiology, diagnosis, and treatment," Current Opinion in Rheumatology, vol. 16, no. 4, pp. 443-449, 2004.

[27] A. Adekile, M. Z. Haider, R. Marouf, and A. D. Adekile, "HLA-DRB1 alleles in $\mathrm{Hb}$ SS patients with avascular necrosis of the femoral head," American Journal of Hematology, vol. 79, no. 1, pp. 8-10, 2005.

[28] J. D. Chang, M. Hur, S. S. Lee, J. H. Yoo, and K. M. Lee, "Genetic background of nontraumatic osteonecrosis of the femoral head in the Korean population," Clinical Orthopaedics and Related Research, vol. 466, no. 5, pp. 1041-1046, 2008.

[29] Y. C. Chao, S. J. Wang, H. C. Chu, W. K. Chang, and T. Y. Hsieh, "Investigation of alcohol metabolizing enzyme genes in Chinese alcoholics with avascular necrosis of hip joint, pancreatitis and cirrhosis of the liver," Alcohol and Alcoholism, vol. 38, no. 5, pp. 431-436, 2003.

[30] W. M. Chen, Y. F. Liu, M. W. Lin et al., "Autosomal dominant avascular necrosis of femoral head in two Taiwanese pedigrees and linkage to chromosome 12q13," American Journal of Human Genetics, vol. 75, no. 2, pp. 310-317, 2004.

[31] X. L. Dai, J. M. Hong, B. Oh et al., "Association analysis of Tissue factor pathway inhibitor polymorphisms and haplotypes with Osteonecrosis of the femoral head in the Korean population," Molecules and Cells, vol. 26, no. 5, pp. 490-495, 2008.

[32] C. J. Glueck, R. Freiberg, T. Tracy, D. Stroop, and P. Wang, "Thrombophilia and hypofibrinolysis: pathophysiologies of osteonecrosis," Clinical Orthopaedics and Related Research, no. 334, pp. 43-56, 1997.

[33] C. J. Glueck, R. A. Freiberg, S. Boppana, and P. Wang, "Thrombophilia, hypofibrinolysis, the eNOS T-786C polymorphism, and multifocal osteonecrosis," Journal of Bone and Joint Surgery, vol. 90, no. 10, pp. 2220-2229, 2008.

[34] C. J. Glueck, R. A. Freiberg, R. N. Fontaine, T. Tracy, and P. Wang, "Hypofibrinolysis, thrombophilia, osteonecrosis," Clinical Orthopaedics and Related Research, no. 386, pp. 19-33, 2001.

[35] C. J. Glueck, R. A. Freiberg, J. Oghene, R. N. Fontaine, and P. Wang, "Association between the T-786C eNOS polymorphism and idiopathic osteonecrosis of the head of the femur," Journal of Bone and Joint Surgery, vol. 89, no. 11, pp. 24602468, 2007.

[36] G. Hadjigeorgiou, E. Dardiotis, M. Dardioti, A. Karantanas, A. Dimitroulias, and K. Malizos, "Genetic association studies in osteonecrosis of the femoral head: mini review of the literature," Skeletal Radiology, vol. 37, no. 1, pp. 1-7, 2008.

[37] W. He and K. Li, "Incidence of genetic polymorphisms involved in lipid metabolism among Chinese patients with osteonecrosis of the femoral head," Acta orthopaedica, vol. 80, no. 3, pp. 325-329, 2009.

[38] J. M. Hong, T. H. Kim, H. J. Kim, E. K. Park, E. K. Yang, and S. Y. Kim, "Genetic association of angiogenesis- and hypoxia-related gene polymorphisms with osteonecrosis of the femoral head," Experimental and Molecular Medicine, vol. 42, no. 5 , pp. 376-385, 2010. 
[39] D. S. Hungerford and L. C. Jones, "Asymptomatic osteonecrosis: should it be treated?" Clinical Orthopaedics and Related Research, no. 429, pp. 124-130, 2004.

[40] L. C. Jones, M. A. Mont, T. B. Le et al., "Procoagulants and osteonecrosis," Journal of Rheumatology, vol. 30, no. 4, pp. 783-791, 2003.

[41] T. H. Kim, J. I. Baek, J. M. Hong et al., "Significant association of SREBP-2 genetic polymorphisms with avascular necrosis in the Korean population," BMC Medical Genetics, vol. 9, article 94, 2008.

[42] T. H. Kim, J. M. Hong, H. J. Kim, E. K. Park, and S. Y. Kim, "Lack of association of MTHFR gene polymorphisms with the risk of osteonecrosis of the femoral head in a Korean population," Molecules and Cells, vol. 29, no. 4, pp. 343-348, 2010.

[43] T. H. Kim, J. M. Hong, J. Y. Lee et al., "Promoter polymorphisms of the vascular endothelial growth factor gene is associated with an osteonecrosis of the femoral head in the Korean population," Osteoarthritis and Cartilage, vol. 16, no. 3, pp. 287-291, 2008.

[44] T. H. Kim, J. M. Hong, B. Oh et al., "Association of polymorphisms in the Interleukin 23 receptor gene with osteonecrosis of femoral head in Korean population," Experimental and Molecular Medicine, vol. 40, no. 4, pp. 418-426, 2008.

[45] T. H. Kim, J. M. Hong, B. Oh et al., "Genetic association study of polymorphisms in the catalase gene with the risk of osteonecrosis of the femoral head in the Korean population," Osteoarthritis and Cartilage, vol. 16, no. 9, pp. 1060-1066, 2008.

[46] T. H. Kim, J. M. Hong, E. S. Shin et al., "Polymorphisms in the Annexin gene family and the risk of osteonecrosis of the femoral head in the Korean population," Bone, vol. 45, no. 1, pp. 125-131, 2009.

[47] K. H. Koo, J. S. Lee, Y. J. Lee, K. J. Kim, J. J. Yoo, and H. J. Kim, "Endothelial nitric oxide synthase gene polymorphisms in patients with nontraumatic femoral head osteonecrosis," Journal of Orthopaedic Research, vol. 24, no. 8, pp. 1722-1728, 2006.

[48] M. Kuribayashi, M. Fujioka, K. A. Takahashi et al., "Combination analysis of three polymorphisms for predicting the risk for steroid-induced osteonecrosis of the femoral head," Journal of Orthopaedic Science, vol. 13, no. 4, pp. 297-303, 2008.

[49] H. Pierre-Jacques, C. J. Glueck, M. A. Mont, and D. S. Hungerford, "Familial heterozygous protein-s deficiency in a patient who had multifocal osteonecrosis: a case report," Journal of Bone and Joint Surgery, vol. 79, no. 7, pp. 1079$1084,1997$.

[50] C. G. Zalavras, G. Vartholomatos, E. Dokou, and K. N. Malizos, "Genetic background of osteonecrosis: associated with thrombophilic mutations?" Clinical Orthopaedics and Related Research, no. 422, pp. 251-255, 2004.

[51] C. J. Glueck, R. A. Freiberg, and P. Wang, "Heritable thrombophilia-hypofibrinolysis and osteonecrosis of the femoral head," Clinical Orthopaedics and Related Research, vol. 466, no. 5, pp. 1034-1040, 2008.

[52] J. P. Jones Jr., "Fat embolism, intravascular coagulation, and osteonecrosis," Clinical Orthopaedics and Related Research, no. 292, pp. 294-308, 1993.

[53] Q. Cui, G. J. Wang, and G. Balian, "Steroid-induced adipogenesis in a pluripotential cell line from bone marrow," Journal of Bone and Joint Surgery, vol. 79, no. 7, pp. 1054-1063, 1997.

[54] Q. Cui, G. J. Wang, C. C. Su, and G. Balian, "Lovastatin prevents steroid induced adipogenesis and osteonecrosis,"
Clinical Orthopaedics and Related Research, no. 344, pp. 8-19, 1997.

[55] X. Li, Q. Cui, C. Kao, G. J. Wang, and G. Balian, "Lovastatin inhibits adipogenic and stimulates osteogenic differentiation by suppressing PPAR $\gamma 2$ and increasing Cbfa1/Runx 2 expression in bone marrow mesenchymal cell cultures," Bone, vol. 33, no. 4, pp. 652-659, 2003.

[56] X. Li, L. Jin, Q. Cui, G. J. Wang, and G. Balian, "Steroid effects on osteogenesis through mesenchymal cell gene expression," Osteoporosis International, vol. 16, no. 1, pp. 101-108, 2005.

[57] W. Drescher, M. H. Bünger, K. Weigert, C. Bünger, and E. S. Hansen, "Methylprednisolone enhances contraction of porcine femoral head epiphyseal arteries," Clinical Orthopaedics and Related Research, no. 423, pp. 112-117, 2004.

[58] Y. Feng, S. H. Yang, B. J. Xiao et al., "Decreased in the number and function of circulation endothelial progenitor cells in patients with avascular necrosis of the femoral head," Bone, vol. 46, no. 1, pp. 32-40, 2010.

[59] T. Kabata, T. Matsumoto, S. Yagishita, T. Wakayama, S. Iseki, and K. Tomita, "Vascular endothelial growth factor in rabbits during development of corticosteroid-induced osteonecrosis: a controlled experiment," Journal of Rheumatology, vol. 35, no. 12, pp. 2383-2390, 2008.

[60] Y. Kaneshiro, Y. Oda, K. Iwakiri et al., "Low hepatic cytochrome P450 3A activity is a risk for corticosteroidinduced osteonecrosis," Clinical Pharmacology and Therapeutics, vol. 80, no. 4, pp. 396-402, 2006.

[61] M. A. Kerachian, C. Séguin, and E. J. Harvey, "Glucocorticoids in osteonecrosis of the femoral head: a new understanding of the mechanisms of action," Journal of Steroid Biochemistry and Molecular Biology, vol. 114, no. 35, pp. 121-128, 2009.

[62] M. Kitajima, M. Shigematsu, K. Ogawa, H. Sugihara, and T. Hotokebuchi, "Effects of glucocorticoid on adipocyte size in human bone marrow," Medical Molecular Morphology, vol. 40, no. 3, pp. 150-156, 2007.

[63] T. Masada, K. Iwakiri, Y. Oda et al., "Increased hepatic cytochrome P4503A activity decreases the risk of developing steroid-induced osteonecrosis in a rabbit model," Journal of Orthopaedic Research, vol. 26, no. 1, pp. 91-95, 2008.

[64] S. Okazaki, Y. Nishitani, S. Nagoya, M. Kaya, T. Yamashita, and H. Matsumoto, "Femoral head osteonecrosis can be caused by disruption of the systemic immune response via the toll-like receptor 4 signalling pathway," Rheumatology, vol. 48, no. 3, pp. 227-232, 2009.

[65] K. T. Suh, S. W. Kim, H. L. Roh, M. S. Youn, and J. S. Jung, "Decreased osteogenic differentiation of mesenchymal stem cells in alcohol-induced osteonecrosis," Clinical Orthopaedics and Related Research, no. 431, pp. 220-225, 2005.

[66] R. Takano-Murakami, K. Tokunaga, N. Kondo et al., "Glucocorticoid inhibits bone regeneration after osteonecrosis of the femoral head in aged female rats," Tohoku Journal of Experimental Medicine, vol. 217, no. 1, pp. 51-58, 2009.

[67] D. Varoga, W. Drescher, M. Pufe, G. Groth, and T. Pufe, "Differential expression of vascular endothelial growth factor in glucocorticoid-related osteonecrosis of the femoral head," Clinical Orthopaedics and Related Research, vol. 467, no. 12, pp. 3273-3282, 2009.

[68] B. L. Wang, W. Sun, Z. C. Shi et al., "Decreased proliferation of mesenchymal stem cells in corticosteroid-induced osteonecrosis of femoral head," Orthopedics, vol. 31, no. 5, p. $444,2008$. 
[69] Y. Wang, L. Yin, Y. Li, P. Liu, and Q. Cui, "Preventive effects of puerarin on alcohol-induced osteonecrosis," Clinical Orthopaedics and Related Research, vol. 466, no. 5, pp. 1059-1067, 2008.

[70] R. S. Weinstein, R. W. Nicholas, and S. C. Manolagas, "Apoptosis of osteocytes in glucocorticoid-induced osteonecrosis of the hip," Journal of Clinical Endocrinology and Metabolism, vol. 85, no. 8, pp. 2907-2912, 2000.

[71] L. Yin, Y. B. Li, and Y. S. Wang, "Dexamethasone-induced adipogenesis in primary marrow stromal cell cultures: mechanism of steroid-induced osteonecrosis," Chinese Medical Journal, vol. 119, no. 7, pp. 581-588, 2006.

[72] C. J. Glueck, R. A. Freiberg, A. Crawford et al., "Secondhand smoke, hypofibrinolysis, and Legg-Perthes disease," Clinical Orthopaedics and Related Research, no. 352, pp. 159-167, 1998.

[73] T. Asano, K. A. Takahashi, M. Fujioka et al., "ABCB1 C3435T and G2677T/A polymorphism decreased the risk for steroidinduced osteonecrosis of the femoral head after kidney transplantation," Pharmacogenetics, vol. 13, no. 11, pp. 675682, 2003.

[74] J. W. Pritchett, "Statin therapy decreases the risk of osteonecrosis in patients receiving steroids," Clinical Orthopaedics and Related Research, no. 386, pp. 173-178, 2001.

[75] C. J. Glueck, R. A. Freiberg, L. Sieve, and P. Wang, "Enoxaparin prevents progression of Stages I and II osteonecrosis of the hip," Clinical Orthopaedics and Related Research, no. 435, pp. 164-170, 2005.

[76] J. P. Jones Jr., "Fat embolism and osteonecrosis," Orthopedic Clinics of North America, vol. 16, no. 4, pp. 595-633, 1985.

[77] J. Paul-Jones Jr., "Intravascular coagulation and osteonecrosis," Clinical Orthopaedics and Related Research, no. 277, pp. 41-53, 1992.

[78] J. P. Jones Jr., "Alcoholism, hypercortisonism, fat embolism and osseous avascular necrosis. 1971," Clinical Orthopaedics and Related Research, no. 393, pp. 4-12, 2001.

[79] G. J. Wang, Q. Cui, and G. Balian, "The pathogenesis and prevention of steroid induced osteonecrosis," Clinical Orthopaedics and Related Research, no. 370, pp. 295-310, 2000.

[80] G. J. Wang, D. E. Sweet, and S. I. Reger, "Fat-cell changes as a mechanism of avascular necrosis of the femoral head in cortisone-treated rabbits," Journal of Bone and Joint Surgery, vol. 59, no. 6, pp. 729-735, 1977.

[81] S. Day, R. F. Ostrum, E. Y. S. Chao, C. T. Rubin, H. T. Aro, and T. A. Einhorn, "Bone injury, regeneration and repair," in Orthopaedic Basic Science: Biology and Biomechanics of the Musculoskeletal System, J. Buckwalter, T. A. Einhorn, and S. R. Simon, Eds., pp. 372-375, American Academy of Orthopaedic Surgeons, Rosemont, Ill, USA.

[82] M. J. Glimcher and J. E. Kenzora, "The biology of osteonecrosis of the human femoral head and its clinical implications: II. The pathological changes in the femoral head as an organ and in the hip joint," Clinical Orthopaedics and Related Research, vol. 139, pp. 283-312, 1979.

[83] M. J. Glimcher and J. E. Kenzora, "The biology of osteonecrosis of the human femoral head and its clinical implication: I. Tissue biology," Clinical Orthopaedics and Related Research, vol. 138, pp. 284-309, 1979.

[84] M. J. Glimcher and J. E. Kenzora, "The biology of osteonecrosis of the human femoral head and its clinical implications. III. Discussion of the etiology and genesis of the pathological sequelae; comments on treatment," Clinical Orthopaedics and Related Research, vol. 140, pp. 273-312, 1979.
[85] D. B. Phemister, "Repair of bone in the presence of aseptic necrosis resulting from fractures, transplantations, and vascular obstruction," Journal of Bone and Joint Surgery, vol. 87, no. 3, p. 672, 2005.

[86] D. B. Phemister, "Treatment of the necrotic head of the femur in adults," The Journal of Bone \& Joint Surgery, vol. 1, pp. 5566, 1949.

[87] F. A. Chandler, "Coronary disease of the hip. 1949," Clinical Orthopaedics and Related Research, no. 386, pp. 7-10, 2001.

[88] T. Atsumi, Y. Kuroki, and K. Yamano, "A microangiographic study of idiopathic osteonecrosis of the femoral head," Clinical Orthopaedics and Related Research, no. 246, pp. 186-194, 1989.

[89] R. L. Cruess, "Osteonecrosis of bone: current concepts as to etiology and pathogenesis," Clinical Orthopaedics and Related Research, vol. 208, pp. 30-39, 1986.

[90] D. S. Hungerford and T. M. Zizic, "Pathogenesis of ischemic necrosis of the femoral head," The Hip, pp. 249-262, 1983.

[91] J. P. Jones Jr. and A. R. Behnke Jr., "Prevention of dysbaric osteonecrosis in compressed air workers," Clinical Orthopaedics and Related Research, vol. 130, pp. 118-128, 1978.

[92] T. Asano, K. A. Takahashi, M. Fujioka et al., "Genetic analysis of steroid-induced osteonecrosis of the femoral head," Journal of Orthopaedic Science, vol. 8, no. 3, pp. 329-333, 2003.

[93] C. J. Glueck, R. N. Fontaine, R. Gruppo et al., "The plasminogen activator inhibitor-1 gene, hypofibrinolysis, and osteonecrosis," Clinical Orthopaedics and Related Research, no. 366, pp. 133-146, 1999.

[94] S. Inoue, M. Horii, T. Asano et al., "Risk factors for nontraumatic osteonecrosis of the femoral head after renal transplantation," Journal of Orthopaedic Science, vol. 8, no. 6, pp. 751756, 2003.

[95] F. R. Al-Mousawi and A. A. Malki, "Managing femoral head osteonecrosis in patients with sickle cell disease," Surgeon, vol. 5, no. 5, pp. 282-289, 2007.

[96] A. De Gheldere, R. Ndjoko, P. L. Docquier, M. Mousny, and J. J. Rombouts, "Orthopaedic complications associated with sickle-cell disease," Acta Orthopaedica Belgica, vol. 72, no. 6, pp. 741-747, 2006.

[97] S. P. Eholié, M. Ouiminga, E. Ehui et al., "Avascular osteonecrosis of the femoral head in three West African HIVinfected adults with heterozygous sickle cell disease," Antiviral Therapy, vol. 14, no. 7, pp. 1011-1014, 2009.

[98] M. Mukisi-Mukaza, O. Manicom, C. Alexis, K. Bashoun, M. Donkerwolcke, and F. Burny, "Treatment of Sickle cell disease's hip necrosis by core decompression: a prospective casecontrol study," Orthopaedics and Traumatology: Surgery and Research, vol. 95, no. 7, pp. 498-504, 2009.

[99] A. Björkman, P. J. Svensson, A. Hillarp, I. M. Burtscher, A. Rünow, and G. Benoni, "Factor V Leiden and prothrombin gene mutation: risk factors for osteonecrosis of the femoral head in adults," Clinical Orthopaedics and Related Research, no. 425, pp. 168-172, 2004.

[100] J. W. Kemper, A. H. Baggenstoss, and C. H. Slocumb, "The relationship of therapy with cortisone to the incidence of vascular lesions in rheumatoid arthritis," Annals of Internal Medicine, vol. 5, pp. 831-851, 1957.

[101] K. H. Koo, R. Kim, Y. S. Kim et al., "Risk period for developing osteonecrosis of the femoral head in patients on steroid treatment," Clinical Rheumatology, vol. 21, no. 4, pp. 299303, 2002.

[102] K. Nagasawa, Y. Tada, S. Koarada et al., "Very early development of steroid-associated osteonecrosis of femoral head 
in systemic lupus erythematosus: prospective study by MRI," Lupus, vol. 14, no. 5, pp. 385-390, 2005.

[103] D. E. Fisher, "The role of fat embolism in the etiology of corticosteroid induced avascular necrosis: clinical and experimental results," Clinical Orthopaedics and Related Research, vol. 130, pp. 68-80, 1978.

[104] E. W. Gold, O. D. Fox, S. Weissfeld, and P. H. Curtiss, "Corticosteroid-induced avascular necrosis: an experimental study in rabbits," Clinical Orthopaedics and Related Research, vol. 135, pp. 272-280, 1978.

[105] K. Miyanishi, T. Yamamoto, T. Irisa et al., "Bone marrow fat cell enlargement and a rise in intraosseous pressure in steroid-treated rabbits with osteonecrosis," Bone, vol. 30, no. 1, pp. 185-190, 2002.

[106] J. J. P. Warner, J. H. Philips, G. L. Brodsky, and T. S. Thornhill, "Studies of nontraumatic osteonecrosis. Manometric and histologic studies of the femoral head after chronic steroid treatment: an experimental study in rabbits," Clinical Orthopaedics and Related Research, no. 225, pp. 128-140, 1987.

[107] R. S. Weinstein, R. L. Jilka, A. Michael Parfitt, and S. C. Manolagas, "Inhibition of osteoblastogenesis and promotion of apoptosis of osteoblasts end osteocytes by glucocorticoids potential mechanisms of their deleterious effects on bone," Journal of Clinical Investigation, vol. 102, no. 2, pp. 274-282, 1998.

[108] Q. Cui, G. J. Wang, and G. Balian, "Pluripotential marrow cells produce adipocytes when transplanted into steroidtreated mice," Connective Tissue Research, vol. 41, no. 1, pp. 45-56, 2000.

[109] W. Drescher, T. Schneider, C. Becker et al., "Effect of methylprednisolone on reperfusion after femoral head ischemia," Clinical Orthopaedics and Related Research, no. 402, pp. 270277, 2002.

[110] Q. Zhong, S. Sridhar, L. Ruan et al., "Multiple melanocortin receptors are expressed in bone cells," Bone, vol. 36, no. 5, pp. 820-831, 2005.

[111] K. Matsuo, T. Hirohata, Y. Sugioka, M. Ikeda, and A. Fukuda, "Influence of alcohol intake, cigarette smoking, and occupational status on idiopathic osteonecrosis of the femoral head," Clinical Orthopaedics and Related Research, no. 234, pp. 115123, 1988.

[112] D. T. Felson and J. J. Anderson, "Across-study evaluation of association between steroid dose and bolus steroids and avascular necrosis of bone," The Lancet, vol. 1, no. 8538, pp. 902-905, 1987.

[113] D. Weldon, "The effects of corticosteroids on bone: osteonecrosis (avascular necrosis of the bone)," Annals of Allergy, Asthma and Immunology, vol. 103, no. 2, pp. 91-98, 2009.

[114] S. Iida, Y. Harada, K. Shimizu et al., "Correlation between bone marrow edema and collapse of the femoral head in steroid-induced osteonecrosis," American Journal of Roentgenology, vol. 174, no. 3, pp. 735-743, 2000. 


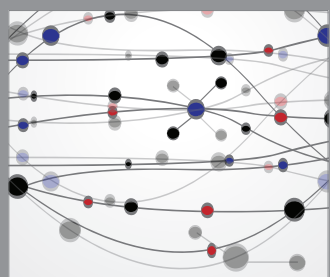

The Scientific World Journal
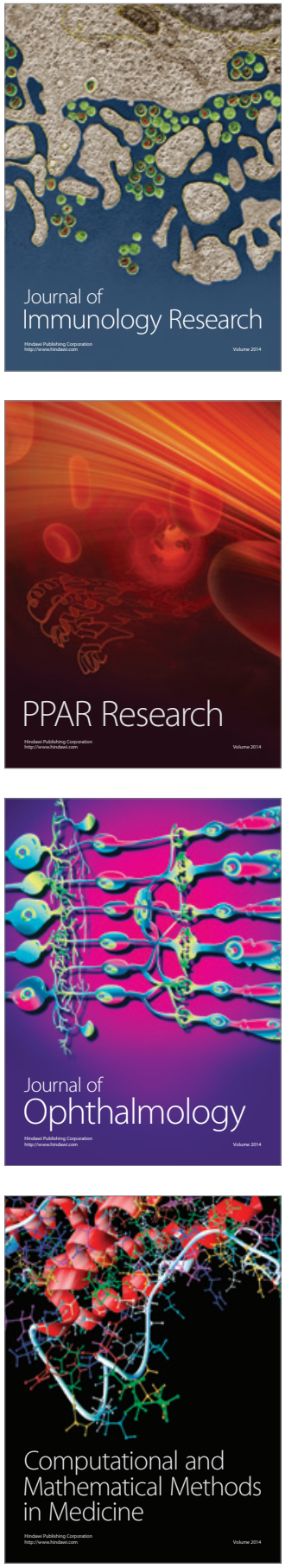

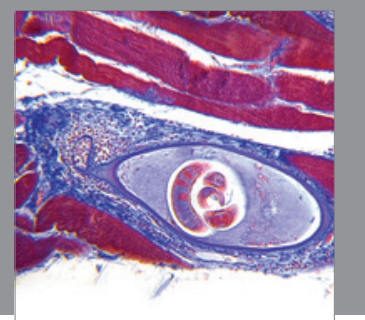

Gastroenterology

Research and Practice
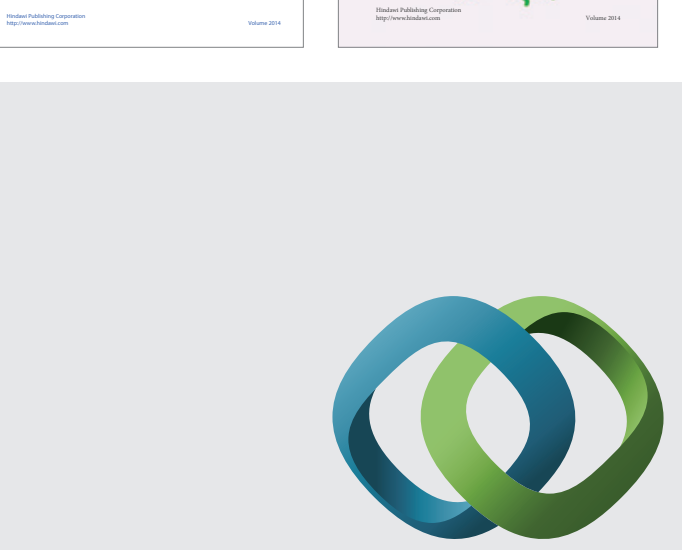

\section{Hindawi}

Submit your manuscripts at

http://www.hindawi.com
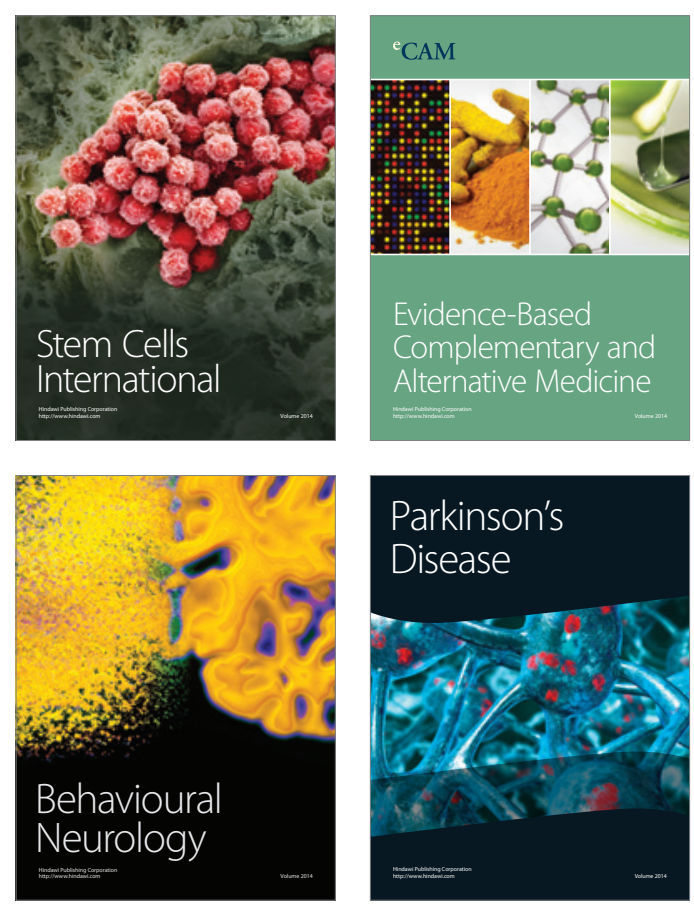

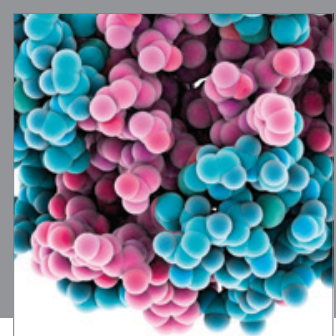

Journal of
Diabetes Research

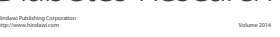

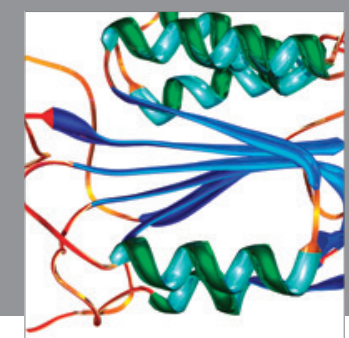

Disease Markers
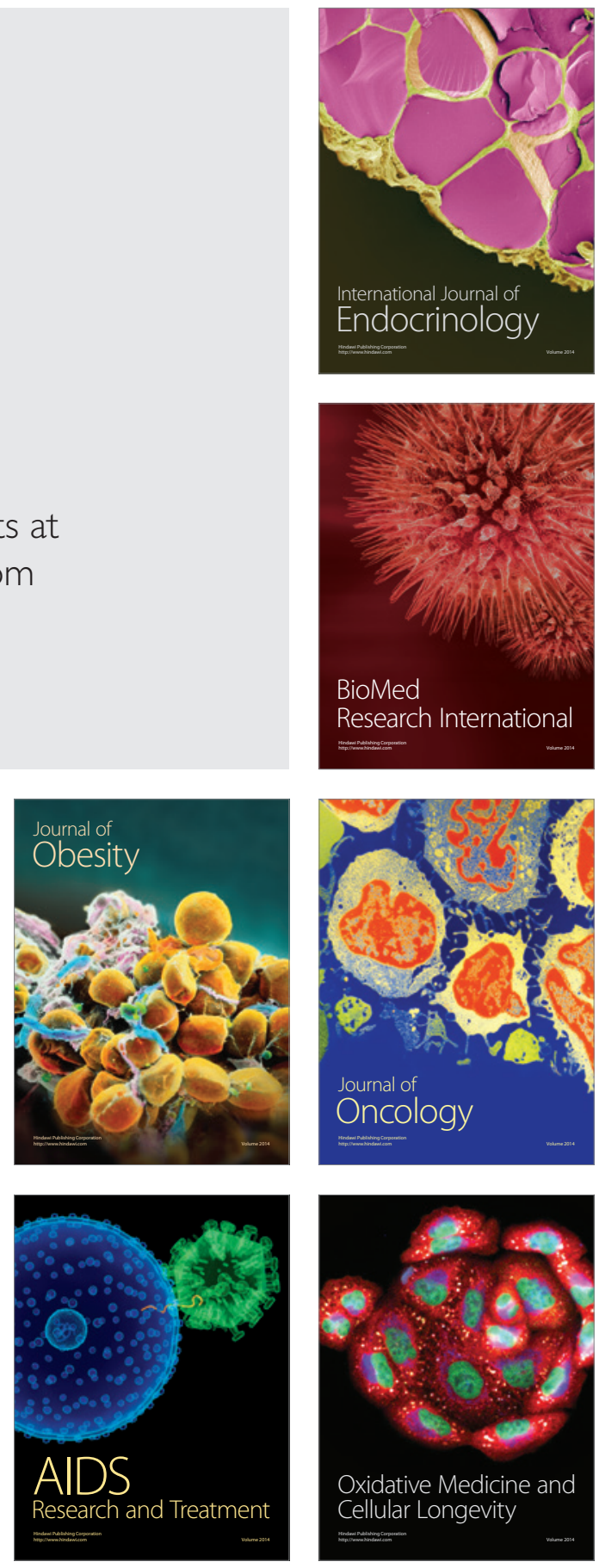